\title{
BPM in the analysis of sale energy electric
}

\section{BPM en el análisis de venta de energía eléctrica}

GONZÁLEZ-RAMÍREZ, Claudia Teresa†*, COLÍN-MORALES, José Manuel, VALDESPINOMORA, Rebeca and SÁNCHEZ-RIVERA, Nubelina

Tecnológico Nacional de México / Instituto Tecnológico de Zitácuaro en Av. Tecnológico No. 186 Manzanillos, C.P. 61534 H. Zitácuaro.Michoacán.

ID $1^{\text {st }}$ Author: Claudia Teresa, González-Ramírez / ORC ID: 0000-0002-4106-4583, Research ID Thomson: G-6313-2019, Open ID: 102182046108513149954

ID $1^{\text {st }}$ Co-author: José Manuel, Colín-Morales / ORC ID: 0000-0002-5821-3573

ID $2^{\text {nd }}$ Co-author: Rebeca, Valdespino-Mora / ORC ID: 0000-0002-4134-1691

ID $3^{\text {rd }}$ Co-author: Nubelina, Sánchez-Rivera / ORC ID: 0000-0003-1492-8515

DOI: $10.35429 /$ JRE.2021.15.5.23.28

Received June 30, 2021; Accepted October 30, 2021

\section{Resumen}

En este artículo se presentan los resultados de una investigación realizada en la agencia Zitácuaro venta de energía, con la ideología BPM la cual robustecen los procesos en una organización, se tornan más transparentes y manejables por todos. En combinación con la ingeniería de software se encargan de transformar, definir, ejecutar y gestionar procesos y tareas, aportando soluciones y mejoras, éstas transformaciones en base para el valor agregado, generando en los clientes satisfacción, por lo que si se fortalecen estas transformaciones se estará incidiendo en las mejoras de los procesos, enfatizando que provee resultados satisfactorios cuantitativos .Los resultados en las ventas han sido de gran impacto en la región oriente de Michoacán.

BPM, Mejora de procesos, Transparente

\begin{abstract}
This article presents the results of an investigation carried out in the agency Zitácuaro for sale of energy, with the BPM ideology which strengthens the processes in an organization, becomes more transparent and manageable by all. In combination with software engineering, they are responsible for transforming, defining, executing and managing processes and tasks, providing solutions and improvements, these transformations based on added value, generating customer satisfaction, so if these transformations are strengthened, It will be influencing process improvements, emphasizing that it provides satisfactory quantitative results. Sales results have been of great impact in the eastern region of Michoacán.
\end{abstract}

BPM, Process improvement, Transparente 


\section{Introduction}

At present, with the technological advances that are presented day by day, it is easier to manage the information generated by an organization, a large amount of information is operated which must be archived, consulted, eliminated or modified, all this in order to achieve their objectives and goals, make use of various analyzes, from filtering and eliminating those data that are not useful, thus facilitating the operations and processes of a company, improving the quality and the times that these entail. Requiring technological solutions from clients to enhance long-term business growth, allowing BPM (Business Process Management) to favor the management of business processes as a strategic technique, which provides the generation and control of changes in an agile way, timely and reliable for the achievement of the objectives of the company.

With this ideology, BPM strengthens the processes in an organization, they become more transparent and manageable by all those involved in the organization, if with the focus of improving processes continuously and in combination with software engineering they are in charge of transforming, define, execute and manage processes and tasks, providing solutions and improvements, many transformations are the basis of an organization, they are the added value, generating that its customers are satisfied, and not only external customers but also internal customers, an organization.

It has its processes duly interrelated being strengthened to make changes in improvements that provide satisfactory quantitative and qualitative results. The implementation of the BPM stream gives us a positive impact on the organization, reflecting an increase in its income, more productive and satisfied employees, improvement of customer service processes and quality improvement. As such, BPMN is a flowchart-based notation for defining business processes, from the simplest to the most complex and sophisticated to support process execution. Since BPMN is a standard notation, it incorporates a large number of terms used in the description of the modeling process that are of great importance. With BPM tools, an organization has the possibility of defining its processes in a computer application, organizing information and people's work, controlling their execution in real time and through adequate monitoring.
The management of a company through a computer system can be optimized with processes designed and constantly monitored, which brings advantages to the organization with viable information, data collection facilities and help in making tactical and strategic decisions of a company. agile and assertive way. BPM is a set of methods, tools and technologies used to design, represent, analyze and control operational business processes.

\section{Justification}

The energy sales of the Zitácuaro agency in the various routes within its sectors can be variable, based on different factors such as seasons, users, places, among others. However, based on comparative points with past periods, as well as the target market set by the company; In some of these routes, sales are reduced or kept to a minimum, so that sometimes the target market is not reached.

\section{Methodology}

BPM encompasses people, systems, functions, businesses, customers, suppliers and partners (Garimella 2008). It is considered as a technological strategy based on the excellent efficient and effective articulation between modeling, its execution and the measurement of the same that Ana better takes decision-making and is an approach focused on processes to improve performance that combines information technologies with process and governance methodologies.BPM technology is considered as a strategy for the management of business processes and an improvement of business execution from the effective and efficient articulation between their modeling, execution and measurement, generating better decisionmaking and business performance.

Business process management (BPM) has been used as a broader term to reflect the fact that business processes Business activities may or may not involve human participants, cross organizational boundaries, and require a high degree of flexibility (Weber, Mutschler, \& Reichert 2010). One of the important drivers for business information systems is business processes, based on overcoming the drawbacks of functional overspecialization and the lack of process control (Mutschler, Weber, \& Reichert, 2009). 
The energy supplier company is a commercial business, focused on the sale and distribution of electrical energy; being the leading company at the national level and one of the most important worldwide. Being the main supplier of electricity at the national level, it maintains certain sales goals for its different regions and established routes. But these goals are not always achieved by various factors, whether of the company or outside of it; These may include illicit uses, bad measurements, user reductions, among others.

\section{Problematic}

Filter routes with energy sales (KWH) that do not meet the sales goals set by the company. Select routes where there is the possibility of illicit uses or bad measurements by meters. Analyzelas reducciones en las ventas de energía based on previous billings, to determine the cause of these either by users or for some other reason. Filter routes whose sales and energy reductions have decreased and have not been based on users Filter outdated meters that could generate a bad measurement in energy consumption, based on the year of its belonging lot Calculate more quickly and efficiently the billing quality of the various sectors that it has.

\section{Hypothesis}

The implementation of an information system with a BPM tool controls the sales control processes of an agency.

\section{Independent variable}

The implementation of an information system with BPM

\section{Dependent variable}

Control of sales processes by route

\section{Methodology to be developed}

Once the psychological and formal commitments with the head of the area are established, the object of change is identified to achieve the desired state through logistical assurance, relationship building and understanding of the situation.

\section{Diagnosis:}

The determination of the diagnosis is based on the application of 2 instruments:

Diagnosis for Quality. It is important to first determine the components that are causing the errors or weaknesses in the services provided by the organization with respect to its clients, starting with the registered failures of previous services and that experts applied for the solution. Subsequently, the diagnosis of the quality of service of the company is carried out to know the perception of the internal and external client, the results that are They obtain facilitate identifying the necessary aspects for the development of a strategic plan.

Process for Organizational Development. Organizational development refers to the effort to improve capacities and skills in solving organizational problems to face changes in their external and internal environment (Ferrer Pérez, Luis 1976). Therefore, the application of organizational development is essential when there are real needs for change, modifications that require the organization to move forward and not stagnate, it is regularly difficult to accept changes, and for this, organizational development is applied.The organizational development process in an organization is a program, which must consider the following:

- $\quad$ An internal diagnosis, to detect where the problem is, in the organization, applying the solution.

- Gathering as much information as possible to make the diagnosis is the structure organizational structure, the direction and the processes that the organization executes.

- $\quad$ Planning application, taking into account those involved within the company.

- Monitoring and evaluation.

\section{Conceptual:}

Implement a system for the analysis with BPM of energy sales by route within the Zitácuaro agency; analyzing the values obtained in past months evaluating them with current figures to see if the goal in sales per route is achieved; as well as evaluating various meters within the route for possible repairs and modernizations. 


\section{Design:}

For the development of this system, the Java programming language was used, its robustness, the support of the industry and its easy portability have made Java one of the languages with the greatest growth and breadth of use in different areas of the computer industry. Computing. To manage the database, the SQL language is used; together with the MySQL database manager.

BPM model, description of the actions of a system from the user's point of view with a business focus. For system developers, this is a valuable tool, as it is a successful technique to obtain the system requirements from the user's point of view.

\section{Development}

The interface is done in a simple and intuitive way so that it can be operated smoothly and easily.

\section{Implementation}

The company has weak sales targets (identified in the formal commitments phase). Once granted, explained and trained on the BPM ideology with the main stakeholders, they understand that it is essential for the organization to seek to recognize the processes that are executed in order to measure and manage them, so that it is possible to make improvements and evolutions in the processes.

Being defined by all those involved (experts from each of their areas) as follows in figure 1 . The master sales process is considered in five main stages: request, service, routes, assignments and billing, in each of the stages are carried out own activities that according to the diagnosis and the experts of the solution, the activities to be developed in each of them were proposed, using TIC,to streamline the process, since one of the weaknesses in sales was customer service time, the complexity of the process to provide a service, but with the focus on business the process was streamlined.

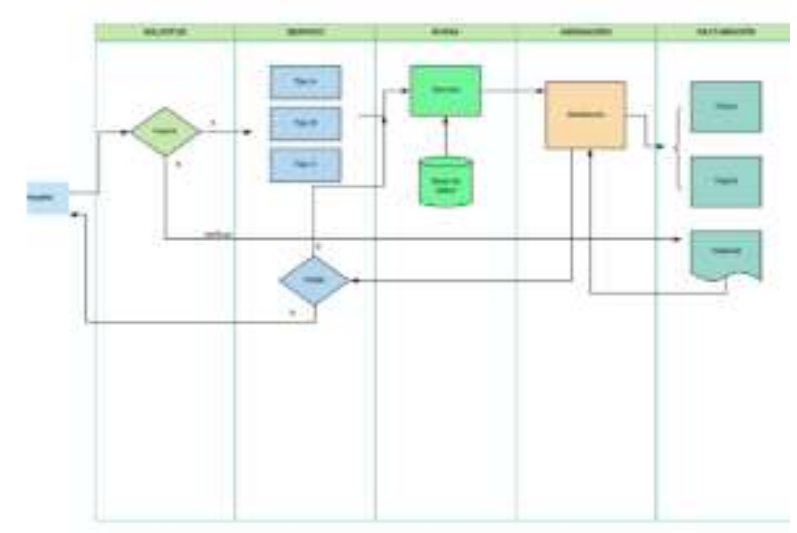

Figure 1 Sales Master Process

Figure 1 is the sample that intervening in the processes is transcendental because changes are generated in the work of the people who develop different roles within the organization, the organizational culture is key to carry out the action plan and allows us $100 \%$ of project success. Therefore, time, dedication and effort are invested to maintain an open, transparent change management communication, to provide complete and adequate information on the need and importance of implementing BPM in their daily work practices.

It should never be considered that everything will be fine to implement a new way of working such as BPM without prior instruction and communication to those involved, because without a doubt we would immediately have chaos, many doubts, resistance and fear in the organization. In addition to making the workers conceive the reason why the change is necessary, showing the importance it has for the organization and why they do things in a certain way. This commitment was adopted from the management to the cleaning person, since absolutely all the members of the organization must be on the same page to achieve the proposed goals, an organization must commit itself throughout it.

The technology is necessary to be implemented in parallel, so in the meetings with those involved, the determination was made to systematize the processes identified in the master sales process in figure 1 , since they are convinced that in this way they will give an opportunity to the achievement of goals in the area. 
The elements of software engineering were attached to the application and at all times the experts in each area provided the precise requirements for their systematization, in addition to that the staff felt satisfied since they were considered in that decision making as end users. The systematization was carried out to the following processes:

$\begin{array}{ll}- & \text { Users } \\ - & \text { Application } \\ - & \text { Types of Services } \\ - & \text { Routes } \\ - & \text { Meter assignment } \\ - & \text { Billing }\end{array}$

Those involved in the area collaborated to reaffirm that there are no separate processes, all are duly related in an atomic way. The product of the systematization is shown below:

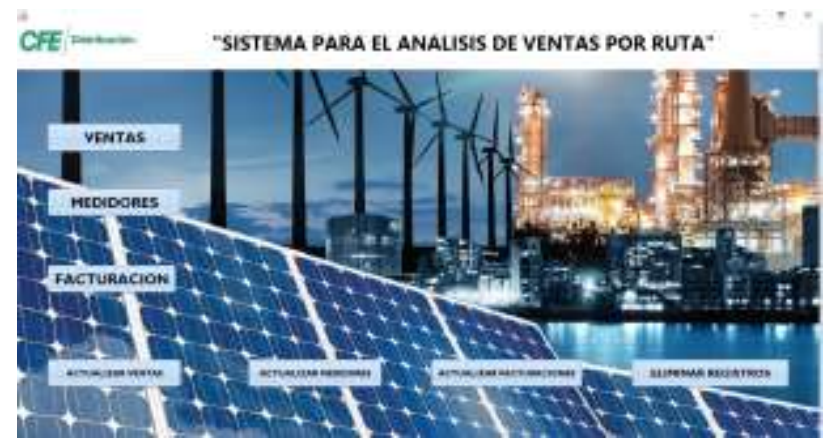

Figure 2 Main menu sales

\section{Results}

The implementation of BPM is a key and strategic factor for reducing costs and increasing investment. The importance of the linkage that businesses must have and the use of appropriate technologies should be highlighted due to the benefits they provide to the organization. BPM technology allows the company an organizational growth from the modeling, administration and optimization of business processes, significantly increasing profits, control of the organization and continuous improvement of the same.

Performance and Times in Processes with technology, although the operations that were carried out to perform the analysis of the information used to be exhaustive, since they were carried out manually and this could take a lot of time which could be used in other operations
An example of this is the analysis of the sales made on the routes, this process could take sporadic work for a whole week since there were a large number of routes and the different parameters had to be analyzed involving up to 15 hours this process, times that have now been considerably reduced; how we can observe in the following graph.

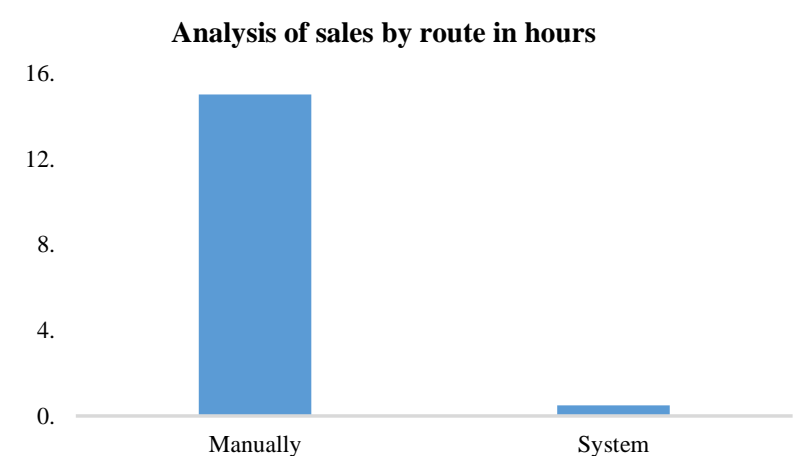

Graph 1 Sales analysis

Although the billing module is one of the most used since the billing quality calculation is a process that is constantly carried out every third day or every week; that in the same way this became tedious and laborious due to the large number of records that are handled regarding billings. As we can see in the following graph, the time that was invested in analyzing the records and calculating the quality of the billing is considerably reduced.

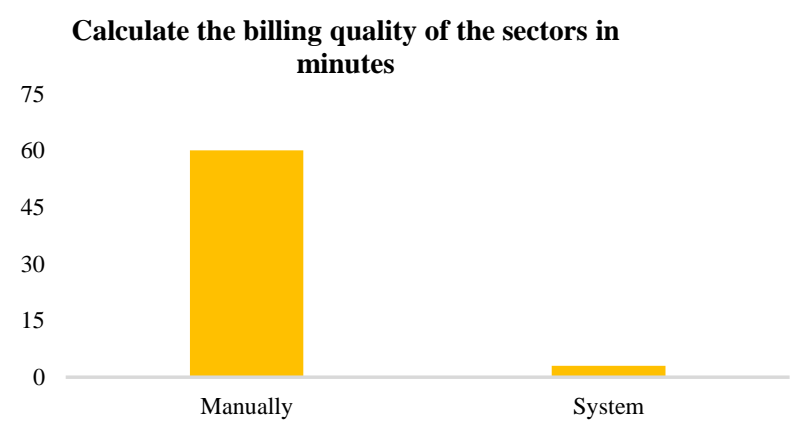

Graph 2 Billing quality

The technology in systems for the analysis of energy sales by route, was of great help for the management of sales within the corresponding department and the organization, since it provides reports with truthful information that is useful for decision-making, allowing In this way, we can improve sales and provide quality service to customers. It monitors the losses that the company has due to illicit uses of energy; It allows to create strategies to increase or recover sales, and in the same way it will allow the modernization of meters that require updating.

GONZÁLEZ-RAMÍREZ, Claudia Teresa, COLÍN-MORALES, José Manuel, VALDESPINO-MORA, Rebeca and SÁNCHEZ-RIVERA, Nubelina. BPM in the analysis of sale energy electric. Journal Renewable Energy. 2021 
As well as it will also allow managing the performance of its workers based on sectors based on the quality of billing they obtain.

\section{Conclusions}

With the results obtained, they denote the need that once the analysis and discovery stage is implemented, the BPM process design in the organization is monitored, since we must be with the continuous improvement approach, and the processes already defined with the time should be improved or changed according to the growth of the organization without leaving aside:

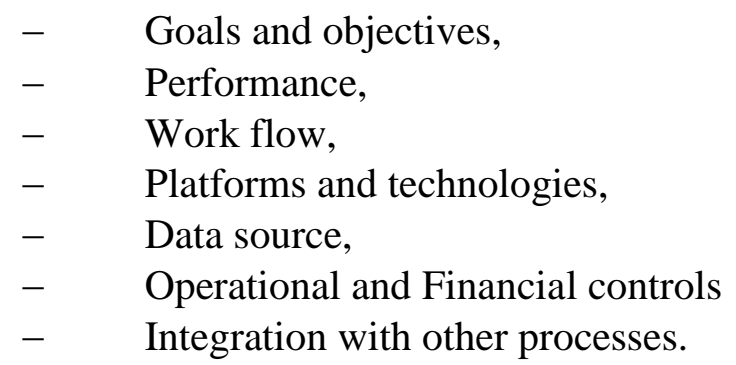

The new business management technologies have taken into account the trajectory that has emerged so far in terms of processes and quality. That is why the design and technological development environments have involved these trends, models and quality measurement methods, making solutions more agile, friendly, graphic and simple, integrating business processes. We can then determine that the hypothesis is fulfilled

\section{Recommendations}

Anyone interested in continuing our research could focus on Organizational Culture with an integral collaborative approach that integrates soft and hard technology and the impact will be on endowing the organization with its own capacity for change.

\section{References}

BPMN Reference Guide and Modeling Understanding and Using BPMN Authors: Stephen A. White and Derek Miers. BPMteca.com

BPM (Business Process Management) How to achieve agility and operational efficiency through BPM and the process-oriented company. Author: José Ramón Pais. BPMteca.com
Pérez , C.( 2007). MySQL for Windows and Linux. Ra-Ma, Bookstore and Editorial Microinformática. Edition 2.

Craig Larman, (2004). "UML and Patterns: An Introduction to Object-Oriented Design and Analysis and the Unified Process, Pearson Publishing. 2nd Edition.

Elias, A., Boumeddane, B., Vera, D. and Jurado, F. (2021). Gasification of solid oil mill waste for cogeneration applications in the Tizi Ouzou region: thermoeconomic evaluation. International Journal of Sustainable Energy, 125.

Fischer, L. (2002). Excellence in BPM Business Process Management in Practice. WfMC.BPMteca.com, "Software Engineering". Editorial Prentice-Hall.

Ferrer, L. (1976). Organizational Development Practical Guide. Mexico: Trillas , pags. 19-20

Gebremeskel, DH, Ahlgren, EO and Beyene, GB (2021). Long-term evolution of energy and electricity demand forecast: the case of Ethiopia. Energy Strategy Reviews, 36, 100671.

Havey, M. (2005). Essential Business Process Modeling. First edition. O'Reilly. [online]. Retrieved March 28, 2020, at: http://www.accid.org/documents/BPM.pdf

Ismail, A. and Mulyaman, D. (2021). Hyundai's investment in electric vehicles in Indonesia: a push-pull factor analysis. Intermestic: Journal of International Studies, 5 (2), 375-394

Pressman R. S. (2010). "Software Engineering: A Practical Approach", Publisher: McGrawHill. Seventh edition

Sommerville Ian, (2005). "Ingeniería del Software". Editorial Addison Wesley. Séptima Edición.

Weber, B., Mutschler, B., \& Reichert, M. (2010). Investigating the effort of using business process management technology: results from a controlled experiment. Science of Computer Programming, 75(5), 292-310. DOI: 10.1016/j.scico.2009.12.003 